\title{
Collaborative diversity in a nanotechnology innovation system: Evidence from the EU Framework Programme
}

\author{
Krsto Pandza ${ }^{\mathrm{a}, *}$, Terry A. Wilkins ${ }^{\mathrm{b}}$, Eva A. Alfoldi ${ }^{\mathrm{c}}$ \\ a Leeds University Business School, The University of Leeds, Maurice Keyworth Building, Leeds LS2 9JT, UK \\ ${ }^{\mathrm{b}}$ NanoManufacturing Institute, The University of Leeds, Houldsworth Building, Leeds LS2 9JT, UK \\ ${ }^{c}$ Manchester Business School, The University of Manchester, Booth Street West, Manchester M15 6PB, UK
}

\section{A R T I C L E I N F O}

Available online 17 June 2011

Keywords:

Nanotechnology

Research policy

EU

Framework Programme

Collaborative research networks

\begin{abstract}
A B S T R A C T
Collaborative diversity is, arguably, an intrinsic characteristic of research networks built on the emergence of general-purpose technologies such as nanotechnology. European research policy, epitomised in Framework Programmes, creates arrangements that institutionalise the development of internationally and institutionally diverse research networks. Motivated by concerns that a high degree of collaborative diversity may create managerial challenges for network members in sharing knowledge across national and institutional borders, we study the configurations of collaborative research networks and consider their international and institutional diversity. We also explore the influence of European policy mechanisms on the international and institutional diversity of collaborative research networks. We conclude that nanotechnology research networks are indeed characterised by a significant degree of collaborative diversity, which in turn exposes a need for participating members to develop strategic capabilities to manage research within diverse networks.
\end{abstract}

(c) 2011 Elsevier Ltd. All rights reserved.

\section{Introduction}

The emergence of nanotechnology as a general-purpose technology (Bresnahan and Trajtenberg, 1995), characterised by its pervasiveness and inherent potential for opening new opportunities, provides fresh challenges for policy-makers, entrepreneurs, managers, engineers and scientists. Policy-makers from different national and transnational innovation systems strive to design policies to realise often highly ambitious promises resulting from the emergence of nanotechnology (Bhat, 2005; Romig et al., 2007). Previous work suggests that entrepreneurs face considerable challenges when venturing to commercialise general-purpose technologies (Thoma, 2008), which is particularly evident in commercialising emergent nano-technologies from an upstream position within a variety of industrial value chains (Maine and Garnsey, 2006). Managers of established companies wrestle with the discontinuous nature of an emergent technological trajectory (Dosi, 1982) that changes dynamics of intra-firm innovation processes (Linton and Walsh, 2008). Engineers and scientists are forced to navigate an interdisciplinary landscape of nanoscience and nanotechnology (Islam and Miyazaki, 2009, 2010).

In this paper, we argue that the emergent and general-purpose nature of nanotechnology demands collaborative research efforts,

\footnotetext{
* Corresponding author. Tel.: +44 113343 4509; fax: +441133434885.

E-mail address: kp@lubs.leeds.ac.uk (K. Pandza).
}

and that nanotechnology innovation networks are therefore highly likely to be characterised by a degree of international and institutional diversity. We introduce European Union Framework Programmes (FP) as an institutional arrangement that sets norms, rules and values for creating internationally and institutionally diverse research networks. Within this context, we explore the international and institutional configurations of nanotechnology research projects and the characteristic roles of partners within collaborative projects, and analyse the mitigating role of different policy instruments for structuring the international and institutional diversity of collaborative networks in nanotechnology.

Existing definitions of nanotechnology provide an insight into the multifaceted nature of this emergent technology and highlight the numerous challenges faced by different members of a nanotechnology innovation system. Authors are largely consistent in defining nanotechnology as the investigation of bottom-up and top-down structural arrangements at a physical size below $100 \mathrm{~nm}$ (nanometres), where the properties of materials, systems and devices differ significantly from those at a larger scale (Kostoff et al., 2007). There is also general agreement that nanotechnology is a platform technology with a potential to transform many industrial sectors, in particular by fostering the convergence between previously separate technology-driven industries (Alencar et al., 2007; Bozeman et al., 2007). The interdisciplinary nature of nanotechnology that spans scientific developments across disciplines is also consistently highlighted (Salerno et al., 2008). Romig et al. (2007) additionally emphasise that nanotechnology may have different impacts on 
different industrial sectors and members of value chains. While nanotechnology is potentially discontinuous and radical, it often provides incremental improvements within existent technological trajectories.

The combination of newness and often asymmetric dispersion of knowledge about nanotechnology (Pandza and Holt, 2007) suggests that relevant knowledge will most likely reside in networks of organisations, rather than in individual members of a technology innovation system (Powell et al., 1996). Such networks can include individuals, firms, universities, research institutes, venture capitalists and public policy agencies (or parts or groups of each). As a technological innovation system is likely to extend beyond a particular national innovation system and institutional environment, international and institutional diversity become its intrinsic properties. Integrating knowledge across national and institutional borders and creating diverse research networks along these two dimensions represent the basic tenet of European Union (EU) research policy embodied in Framework Programmes (FPs). The history of FPs is characterised by a series of institutional changes (Hargrave and Van de Ven, 2006), by which the European Commission (EC) creates institutional arrangements that determine the nature and structure of research collaboration networks funded from EU sources.

The international diversity of collaborative research projects is influenced by two strategic objectives of EU research policy: subsidiarity and cohesion. Under the policy objective of subsidiarity, introduced in FP2 (1987-1991), the EC funds research projects that are most effectively pursued at the EU level by integrating resources from different member states (Kuhlmann, 2001). In practice, this principle is addressed by the condition that research networks funded within a FP must consist of partners from at least three different member states. As such, the EC has effectively institutionalised a degree of international diversity in collaborative research projects. International diversity is further emphasised by the strategic objective of cohesion, which has been central to the introduction of FP6 (2002-2006). By emphasising cohesion, the EC recognises that the technology gap among the EU member states is bigger than the gap between the EU, the USA and Japan (Pavitt, 1998) and is still increasing (Clarysse and Muldur, 2001). Although the EC does not make the participation of so-called 'less favourable countries' a norm for collaborative projects, it certainly favours a balanced international structure (Marin and Siotis, 2008), and applicants for research funding are generally aware that a well-balanced research network makes their application more likely to succeed.

Meanwhile, institutional diversity in EU collaborative research is also influenced by various policy objectives, which include increasing industrial competitiveness, fostering innovation for achieving economic growth and tackling large-scale societal challenges by organising research into strategic thematic priorities. The notion of pre-competitive research, explicitly emphasised in FP4 (1994-1998), highlights the importance of inter-firm collaboration and knowledge sharing (Ahuja, 2000; Luukkonen, 2000), as well as encouraging close and strategic collaboration between industry and university research centres (Santoro and Chakrabarti, 2001). Overall, it is evident that EU policy objectives are aimed at increasing the international and institutional diversity of nanotechnology research networks, which inevitably creates challenges for managing such networks. As Kastrinos (1994) argues, configurations of European research networks determine the ability to shape and control the direction the research projects, calling for more in-depth studies on the configuration of research networks fostered by the FPs.

The remainder of this paper is organised as follows. Section 2 discusses the evolution of EU research policy on nanotechnology. In this section we attempt to depict the policy instruments with the highest impact on international and institutional diversity and position them within the wider context of EU policy development on nanotechnology. In Section 3, we review the issues that may affect the management of international and interinstitutional research collaboration. In Sections 4 and 5, we provide information on our data sources, propose a methodology for exploring collaborative diversity in research projects and present our results. A discussion with policy-relevant conclusions is presented at the end of the paper, in Section 6.

\section{Nanotechnology and EU innovation policy}

The establishment of nanotechnology as a distinct research priority within Framework Programme 6 (FP6) reflects the spirit of the time at the beginning of the 21 st century. The ambitious, coordinated and centralised National Nanotechnology Initiative (NNI) in the USA in 2001 clearly exposed the fragmentation of nanotechnology research in the EU, and strengthened the recognition that the EU cannot remain competitive at a global level without better focusing and coordinating nanotechnology research. FP6 provided a fertile institutional environment for creating a separate research programme dedicated to an emergent technology. It was introduced with ambitious policy objectives to significantly enhance industrial innovation, change the European research landscape through the introduction of the integrated European Research Area (ERA), and create sustainable growth, increased employment and greater social cohesion. This unique confluence of the emergence of a major new technology paradigm, competitive pressures and a new institutional context explains the creation of a focused and integrated EU research policy dedicated to nanotechnology. Table 1 provides a detailed chronology of EU nanotechnology policy and highlights those policy instruments with the greatest impact on diversity and configurations of nanotechnology research networks.

Research policy development in the EU is a highly complex process wherein a myriad of representatives from different EU countries and different institutional environments attempt to shape the structure of the final Work Programme. FP6 introduced European Technology Platforms (ETPs) for providing high-level industrial input into the development of European research policy. At the end of FP6, the number of ETPs was 33, each producing a strategic research agenda that fed into the preparation of a series of annual Work Programmes. ETPs have been a major force for driving industry sector diversity and significantly increasing the range of institutional stakeholders that influence EU research policy development in general and nanotechnology in particular. The EC recognises that some twelve ETPs (e.g. NanoMedicine, Sustainable Chemistry, Future Manufacturing Technologies) have a direct interest in nanotechnology.

FP6, similarly to its predecessors, consists of thematic programmes (TPs) that concentrate on a particular research area and instruments for funding and managing research. Typically, TPs and instruments are structured as vertical and cross-cutting activities. Each TP is managed by an EC Research Directorate and builds its annual operational plan (Work Programme) with input from member states' governments via its Programme Committee and a variety of other stakeholders. It is implemented through various instruments, which are the principal mechanisms for realizing the EU's objectives for international and institutional diversity within the annual operating plans and are defined at the start of each FP. We introduce four instruments that have a strong influence on the configuration of nanotechnology research networks.

Strategic Targeted Research Projects (STREPs) are objectivedriven research projects focused on a single research issue, with a limited scope of activities. For STREPs, relatively small networks (3-4 participant institutions/firms) may suffice, budgets tend to be moderate and projects may last for up to three years. The EC is 
Table 1

Chronology of EU nanotechnology policy.

\begin{tabular}{|c|c|c|c|}
\hline Policy & Action & International collaboration & Inter-institutional collaboration \\
\hline Framework Programme 4 (1994-1997) & $\begin{array}{l}\text { - Nanotechnology was not a } \\
\text { dedicated theme } \\
\text { - It emerged organically through the } \\
\text { New Materials (Area-2) in the } \\
\text { Industrial Technologies Programme, } \\
\text { also known as BRITE-EURAM III } \\
\text { - } € 120 \text { million was ultimately spent } \\
\text { on nanotechnology research }\end{array}$ & $\begin{array}{l}\text { - Shared Cost Actions for collaborative } \\
\text { projects } \\
\text { - Thematic Networks (TN) brought } \\
\text { projects together to share ideas and } \\
\text { best practice: type A (funded FP4 } \\
\text { projects) and type B (not funded by } \\
\text { EC but could lead to new EC } \\
\text { research proposal) }\end{array}$ & $\begin{array}{l}\text { - Shared Cost Actions for collaborative } \\
\text { projects } \\
\text { - Technology stimulation measures } \\
\text { for SMEs to purchase research from } \\
\text { Universities }\end{array}$ \\
\hline
\end{tabular}

Framework Programme 5 (1998-2002)

Framework Programme 6 (2002-2007)

\section{European Forum on Nanotechnology (Euronanoforum)}

2004 Strategic Planning (EC, 2004)

\section{Open Consultation}

2005 Political Communication (EC, 2005a)

2005 FP6 EAG Position Paper (EC, 2005b)

2007 Report on Action Plan (EC, 2007)
- Nanotechnology was a sub-topic (1 of 3 ) of the Cross-cutting Materials Technologies theme within the New

Materials and Production Technologies (NMP)

Programme-its growth remained organic

- €220 million was ultimately spent on nanotechnology research

- Nanotechnology emerged as distinct thematic priority within the NMP Programme and planned as a strategic activity with $€ 347$ million spent

- Total nanotechnology spending reaches $€ 1.4$ billion

Initiates wider debate on future nanotechnology policy development
- Shared Cost Actions for collaborative projects retained as main research funding instrument

- EU Enlargement with 11 new member states

- Networks of Excellence (NoE) replace TNs

- Establishment of the EU Joint Research Centre in 5 different member states

- Integrated European Research Area (ERA)

- Candidate countries sign association agreement (increase of international diversity)

- Mechanisms such as Integrated Project (IP) and Strategic Research Projects (STREPS)

- NoE become ERA NET, ERA NET Plus and Article 169 for EU and member states co-funding

- Emphasises collaboration between old and new member states

- Euronanoforum becomes an annual event managed by the rotating EU presidency promoting internationa collaboration

Shared Cost Actions for collaborative projects retained as main research funding instrument

- Introduction of Expert Advisory Groups (Industry, Academia, Independent Research and Technology Organisations)
- Establishment of European Technology Platforms for engaging industry in shaping the research policy

- Mechanisms such as Integrated Project (IP) and Strategic Research Projects (STREPS) and Networks of Excellence (ERA NET and ERA NET Plus)

- NMP uniquely introduces specific collaborative projects for SMEs

Emphasises need for interinstitutional collaboration - Euronanoforum becomes an annual event promoting institutional collaboration
- Investments into nanotechnology vary considerably across member states

- Mobility of researchers
- Maintaining excellence in scientific research through long-term research collaboration

- Mobility of researchers research

- Consultation with more than 700 experts on formulating and implementing the strategy

- Document on nanotechnology communicated to European Parliament and Social Committee to transfer strategy into coherent action plan

- Expert Advisory Group provides mid-term assessment of the Work Programme and makes recommendation on organisation of EU nanotechnology research

- Analyse implementation of the fouryear action plan for nanotechnology research
- Improve mobility across national borders

- Exposes challenges for managing IP and $\mathrm{NoE}$

Support for transnational networking

- Analysis of global competitiveness

- Limited participation of new member states

- Limited coordination of projects by new member states

- Increase in industrial participation from $18 \%(2003-2004)$ to $37 \%$ in 2006
- Improve mobility across institutional borders

- Increase SMEs involvement in collaborative research

- Integration of resources across universities, research institutes and private sector research centres

\section{Satisfactory engagement from industry \\ - Dedicated IP for SMEs}

- Interdisciplinary training

- Integrating wider social concerns (responsible innovation) 
continuously concerned over SME participation in STREPs, hence the introduction of a special class of STREP projects such as Co-operative Research (CRAFT) and 'Exploratory Awards'. In contrast to STREPs, Integrated Projects (IPs) are characterised by large numbers of partners from various countries and institutional settings, with an emphasis on live demonstration within industrial settings and obvious routes to market. They are large, ambitious projects addressing multiple research issues across an extended network and lasting up to five years. IPs are designed to assemble a critical mass of expertise and resources to address major industrial opportunities or societal issues. By FP5 Nanotechnology (see Table 1) was a sub-topic in its own right as a cross-cutting theme within Key Action-1 of the Growth Programme NMP. It became a strategic emergent technology sub-theme and both IP and STREP projects were feasible. At the start of FP6, the IP was the instrument of choice for the New Materials and Production Technologies (NMP) Directorate, but it was quickly realised that many applications for emergent nanotechnology were too early for IPs and the balance was shifted towards STREPs later in the Framework Programme.

In contrast to STREPs and IPs, Networks of Excellence (NoEs) support joint programmes of activities that go beyond research and require institutional commitment at a strategic level from all partners, in order to achieve sustained integration between network members and the EC in emerging technologies. NoEs are strongly encouraged to be inter-institutional and international, but are targeted predominantly at research institutes and universities. Industry is involved through more indirect arrangements such as steering committees and advisory boards. The term NoE was gradually replaced by the ERA Net. The latter instrument proved useful for nanotechnology. The pathway from NoE to ERA Net was used in FP6 to build a pan-European integration of the member states' national metrology research institutes wherein nanotechnology standards development is a major focus.

Finally, Coordination Actions (CAs) and Specific Support Actions (SSAs) target activities to improve the coordination of research carried out in different contexts and to prepare future actions emerging from existing research, including Work Programme (WP) calls. Since these two instruments fund the coordination and dissemination of existing rather than new research activities, they were combined into a single category Coordination and Support Actions (CSAs) and adopted by the EC for FP7.

It is evident from our discussion that the evolution of EU research policy for nanotechnology is inseparable from efforts to enhance collaborative research by bringing together internationally and institutionally diverse research networks. Inevitably, this avowed collaborative diversity in EU nanotechnology programmes creates challenges for the management of nanotechnology research. We address these issues in the next section.

\section{Issues affecting international and inter-institutional collaboration}

The concept of international collaboration has been explored in various contexts in the literature. These contexts include multinational enterprises (whose subsidiaries are internationally dispersed), strategic alliances between firms, and intra-firm communities of practice (groups defined by a shared domain of interest, profession or objectives) (Lave and Wenger, 1991). The most obvious issues arise from geographical distance between partners, which increases the costs of information transfer and face-to-face communication (De Meyer, 1993) and language differences, which may create information processing difficulties (Welch and Welch, 2008). In the context of FPs, these geographical and language differences may contribute to the creation of smaller informal clusters within the formal collaborative projects, potentially affecting the overall coherence of the project. On a deeper level, international collaboration is likely to be affected by the diverse national, social, cultural and organisational backgrounds of international collaborators, who may have sharply differing norm systems, ideologies, interests of stakeholders and management practices (Hong and O, 2009; Huzzard and Östergren, 2002; Parkhe, 2003; Sirmon and Lane, 2004). Differences between collaborators often manifest themselves in issues of information processing as well as micro-political or intercultural conflict (Kellogg et al., 2006; Mense-Petermann, 2006). In a collaborative project setting such as projects within a FP, such issues are likely to be magnified, as the development of agreements, commitments, standard procedures and shared protocols is taking place in a non-hierarchical, shifting and relatively temporary context (cf. Kellogg et al., 2006).

In addition to international collaborative diversity, a number of projects within FPs involve inter-institutional collaboration between private industry (large firms and SMEs) and public research institutions (universities and research institutes). In such settings, industry players and research institutions gain mutual benefit and learning from collaboration, which complements their internal research and development activities (Hanel and St-Pierre, 2006; Kautt et al., 2007; Rothaermel and $\mathrm{Ku}, 2008$ ). One of the key issues that arise in the context of inter-institutional collaboration is the uncertainty of tangible outcomes. As Pertuzé et al. (2010) note, promising outcomes of joint projects often fail to translate into tangible impacts, a problem termed 'the outcome-impact gap'.

According to Harryson et al. (2008), the fundamental issue in inter-institutional collaboration between firms and research institutions arises from having to reconcile different objectives, timeframes and optimal network structures for innovation. Building on the work of Hansen (1999), the authors argue that a knowledge exploration strategy tends to have a long-term view and works best in open network structures with weak but diverse links between collaborators - conditions most likely to be found in public research institutions. In contrast, a knowledge exploitation strategy tends to be more focused on the short- and medium-term and requires closed networks and strong ties between collaborators-conditions most likely to be found in private firms. This means that in FP projects, collaborative partners may differ in their role and competence during different phases of the research project, which is a potential source of conflict. In addition, Harryson et al. (2008) identify various barriers to learning and efficiency in inter-institutional collaboration, such as lack of adequate resources (on either side), differences in institutional culture, norms and practices, and incompatible reward systems (publications vs. products). To address some of these issues, Santoro and Bierly (2006) provide a comprehensive list of factors such as social connections, trust and technology relatedness as critical for knowledge flows across institutional borders.

Bjerregaard (2010) reports the emergence of institutional convergence consisting of shared cultural space for knowledge exchange between technology-led SMEs and university research groups. Although such cultural micro-cosms foster collaboration, he warns that such institutional convergence may be more difficult to achieve with more mature SMEs, with less exposure to advanced technologies. This is in line with suggestions that increased co-production of technological knowledge often fails to lower the boundaries between public research institutions and industry. Recent evidence suggests that these boundaries are still prevalent and coexistence between different institutional environments is still a case of complementarity rather than of fusion (Murray, 2002; Nikulainen and Palmberg, 2010; Shinn and Lamy, 2006), even within the same national environment (Heinze and Kuhlmann, 2008). Previous studies suggest that reasons for 
inter-institutional collaboration vary significantly among industrial partners and can be determined by factors such as size, age and industrial sector (Luukkonen, 2002; Santoro and Chakrabarti, 2002).

Similar findings emerge from studies exploring the managerial challenges within the specific context of EU collaborative projects. Authors report a sensitive balancing act between hierarchical and decentralised approaches to management (Arranz and Fernandez de Aroyabe, 2006; Vonortas and Spivack, 2006). Davenport et al. (1999) note that the success of research collaborations depends largely on management issues, while Archibugi and Coco (2004) show that companies may be reluctant to collaborate with others within EU sponsored collaborative projects, due to the competitive reasons.

The combination of international and institutional diversity inevitably influences the effectiveness of collaboration in research projects within the EU's FPs. Unsurprisingly, many participants, when asked about their experience of EU-funded research projects, refer to learning about collaboration and managing network relationships as major outcomes of research projects (Laredo, 1998; Luukkonen, 1998). Capability in managing collaborative diversity looms large in calls for participating in FP collaborative projects, and applicants for FP projects are asked to demonstrate a capability in managing the proposed research network, with the assessment of this capability usually contributing $20 \%$ of the overall score for a submitted project proposal. These associated costs for managing networks prompted a fierce critique by Dosi et al. (2006), who argue that EU research policy should concentrate on enhancing scientific excellence and reduce support for 'unproductive' networking activities. Due to collaborative diversity in FP projects, the confirmed need for managerial capability highlights the role of project coordinators. Although project coordinators often outsource the burdensome administrative and project management activities to consultants, they still represent the focal point of a diverse innovation network, orchestrating network activities to ensure knowledge mobility and stability of the network, and balancing value creation amongst partners (Dhanaraj and Parkhe, 2006). The finding that organisations occupying a central position in networks produce more innovations (Tsai, 2001) further legitimises the claim that not all the roles in collaborative research projects are equal, or lead to equal benefits.

The widespread dispersion of knowledge about nanotechnology makes international and inter-institutional collaboration an imperative for nanotechnology-driven innovation, but the resulting network diversity complicates the collaborative process of innovation. This is why a simple recognition that nanotechnology innovation networks, in particular within FPs, are diverse does not suffice. It is important to explore how diverse these networks are and what configurations have emerged; how various policy mechanisms influence the international and institutional diversity of research networks; and how diverse the coordinators of these networks are.

\section{Data sources and method}

\subsection{Data}

The dataset used in this study is assembled from data initially compiled by the EC's Unit G4 Nanoscience and Nanotechnology. The comprehensive database was designed in order to organise the raw data and prepare it for statistical analysis. The dataset provides information on 108 collaborative projects funded in FP6 under the Thematic Area 3. It is divided into two sub-databases, the first one focused on projects $(n=108)$ and the second one on partners
( $n=661)$. For each collaborative project, we collected data about the total funding for the project, the instrument under which the project was funded, the project topic as classified by the EC, and the number of partners in the project. The second database listed all partners, their country of origin and their institutional affiliation. Partners were further divided into old and new member states. Additional desk research was carried out to establish the institutional character of partners. We divided public research organisations into universities $(n=270)$ and research institutes $(n=107)$, while industry partners were divided into large firms $(n=109)$ and SMEs $(n=119)$. Public organisation partners with primary objectives other than research (e.g. museums, hospitals and civic organisations) were classified as other $(n=20)$, and management consultancy partners whose role was limited to project management were grouped separately $(n=36)$. It became obvious early on that some partners participated in more than one project, which led us to create a category named partnerships, representing the total number of project involvements by all partners $(n=1121)$.

We categorised the 108 projects by instrument (STREP, IP, NoE and CSA-see Section 2) and also by the five different research topics for which project proposals were invited. Long-term research into understanding phenomena, mastering processes and developing tools was labelled Fundamentals (1). The topic of Nano-biotechnology (2) is focused on supporting research into the integration of biological and non-biological entities, while the topic of Nano-engineering (3) addresses the development of novel functional and structural materials of superior performance. Handling and Control Devices and Instruments (4) is centred on the development of a new generation of instrumentation for analysis and manufacture at the nano-scale. Finally, the topic Applications (5) focuses on areas such as health and medical systems, chemistry, energy, optics, food and the environment; it aims to foster the potential of nano-technologies in breakthrough applications through the integration of research developments in materials and technological devices.

\subsection{Method}

Prior to statistical analysis, preliminary data exploration was carried out to describe the structure of project coordination and frequency of participation in different instruments by identified types of partners. Where the statistical assumptions of normality and homogeneity of variance were accepted, ANOVA and two-sided pairwise $t$ tests were performed for comparing the participation of academic institutions, research institutes, large companies and SMEs within research projects; otherwise, the nonparametric Wilcoxon test was used. In order to quantify the differences between institutional groups of partners, linear regression analysis was used. The regression residual structure was evaluated graphically using the appropriate diagnostic plots (Crawley, 2003). For exploring the institutional structure of partners between different project topics, Chi-squared goodness-of-fit tests were performed. All the significance levels for multiple comparisons were adjusted using the false discovery rate method. Only test results below $5 \%$ significance levels $(<0.05)$ were considered statistically significant.

In addition, we constructed measures for determining international and institutional diversity for each research project in order to explore the collaborative configurations that emerged in nanotechnology projects within FP6. We started by defining international diversity as a proportional relationship between the number of different countries participating in a specific project and the number of partners involved in the project. Mathematically, the international diversity $D_{i}$ can be expressed as

$D_{i}=F\left(N_{i}, M_{i}\right)=\frac{M_{i}}{N_{i}} \quad$ with $0<D_{i} \leq 1$ 
where $N_{i}$ is defined as the number of partners involved in project $i$ $(i=1,2, \ldots, 108)$ and $M_{i}$ represents the number of countries that collaborate in project $i(i=1,2, \ldots, 108)$. Based on the institutional arrangement that each FP research project requires partners from at least three countries, the above mathematical equation has a constraint $N_{i} \geq 3$ for any given $i$.

This initial formulation conveys a simple logic implying that the maximum international diversity $D$ equals 1 . This is when the number of countries involved in the project equals the number of partners, i.e. each partner originates from a different country. $D$ is also always positive, because $N$ is in practice never infinite. There are 39 different countries represented in this study; however, research networks rarely contain such a large number of partners. As a result, projects with more partners involved will have a tendency towards lower international diversity (more than one partner from the same country), while projects with fewer partners are more likely to be characterised by higher international diversity (one partner from each country). This presents a risk of bias when measuring $D$, unless Eq. (1) is modified. Due to this intrinsic limitation of the simple proportional function for international diversity, we include a tuning factor to relieve the tendency of lower diversity for projects with large number of partners. The international diversity is then expressed as a function

$D_{i}=F\left(N_{i}, M_{i}\right)=\frac{M_{i}}{N_{i}} \times\left[\log \left(\frac{M_{i}}{3}\right)+1\right]$

Eq. (2) assigns more weight to the projects with more partners involved and the upper limit for $D$ can exceed 1 . For example, a project with $N=6$ and $M=4$ results in $D=0.75$ and a project with $N=12$ and $M=8$ has $D=0.95$. This implies the latter is more internationally diverse that the former, although the ratios $M / N$ (1) are identical.

We adapted the notion of biological diversity (Simpson, 1951) to construct the measurement of institutional diversity. Simpson's diversity index is a measure of diversity, which in our case takes into account the number of different types of partners involved in a research project and the relative distribution of different types of partners within the project. The institutional diversity index is therefore defined as

$\mathrm{ID}=1-\sum\left(\frac{n}{N}\right)^{2}$

where $n$ is the total number of partners of a particular type and $N$ is the total number of partners of all types in the research project. Notice that we divide between four institutional types, namely: university, research institute, large firm and SME. This brings the maximum institutional diversity index ID to 0.75 in the case where each partner type is represented equally within the project (e.g. $1,1,1,1$ or $2,2,2,2$ ). For example, if a research project comprises two universities, two research institutes, four large companies and no $\operatorname{SME}(2,2,4,0)$ then the institutional diversity index ID is 0.625 and such a project is considered less institutionally diverse than the above mentioned examples. For technical purposes we multiplied Eq. (3) with a fixed scaling factor $4 / 3$ in order to make the maximum index for institutional diversity ID equal 1.

A scatter plot based on both international diversity and institutional diversity was used to investigate the collaborative diversity of nanotechnology projects.

\section{Results}

Table 2 depicts the variety of international and institutional partners that are engaged in collaborative research projects in nanotechnology within FP6's Theme 3. The structure of international partners is not surprising, with the three European powerhouses
Germany, UK and France contributing slightly over 40\% of all partners in nanotechnology research networks. This share is largely in line with the population demographic of the EU. Among the top three countries, Germany holds the lead with $20 \%$ of all partnerships, which undisputedly puts it at the centre of nanotechnology activities funded by EC. The next group of countries is populated by the Netherlands, Belgium and Ireland, large Mediterranean countries Italy and Spain, Scandinavian countries Sweden, Denmark and Finland, and highly developed Central European countries Austria and Switzerland.

This very rough definition of the second group exposes the need to have a closer look at the contribution of new member states in collaborative research networks in nanotechnology (see Fig. 1). Although new member states make up around $20 \%$ of the EU's total population, they contributed just $7 \%$ of all collaborative partnerships in FP6. This is not surprising, taking into account that these countries joined FP6 for the first time, but it nevertheless raises some questions about international diversity in the context of the policy goal of cohesion. Table 3 shows that small countries tend to take their fair share of project partnerships, with small new member state Slovenia joining the best performing group, made up of highly developed countries, while most other new member states reside in the bottom third of the list, with Poland, Bulgaria and Romania as the least represented countries relative to their population. However, Table 3 should be interpreted with some caution, because it may be partly due to the recognised need by EU research organisations to correctly balance the international diversity of research networks.

Table 4 provides some insights into the institutional diversity of partners. From a competitiveness perspective, the EC is strongly interested in the participation of partners from different institutional backgrounds. Table 4 compares the participation of academic partners, research institutes, large firms and SMEs. The number of partnerships for both academic and research institutes is significantly higher $(p<0.001)$ than that of industry partners, which is not a surprising result. It is interesting that no significant difference was found between large firms and SMEs $(p<0.543)$. Although the number of SMEs in the EU far exceeds the number of large companies, it is still important to see evidence that SMEs are not lagging significantly behind in the number of total partnerships in nanotechnology projects when compared to large companies. In order to quantify the differences between different institutional groups of partners, regression analysis was used. On average, research institutes have the highest number of partnerships, followed closely by academic institutions, both exceeding the total of industry partnerships. However, it is also important to note that the structure of public research institutions is influenced by the characteristics of national innovation systems. For example, the UK is mostly represented by universities (reflecting the nature of the UK system for allocating research funding), while among project partners from France, research institutes are more highly represented than academic institutions.

Next, Fig. 2 and Table 5 address the structure of project coordinators. Project coordinators are instrumental for managing the diversity of research networks. The fact that the top four countries that contribute a total of $50 \%$ of partners also coordinate $56 \%$ of collaborative projects, combined with the finding that new member states coordinate just below $3 \%$ of projects, provides some evidence that the role of coordinators, despite the avowed administrative burden, remains central to the leadership of collaborative networks. It also shows that scientific leadership by larger countries is accompanied by an established capability to manage collaborative research in the area of nanotechnology. Fig. 2 also shows that the bulk of project coordination is performed by universities and research institutes, while companies, regardless of size, rarely have this responsibility. Table 5 indicates that if companies do coordinate 
Table 2

Overview of the international and institutional structure of nanotechnology research projects in FP6.

\begin{tabular}{|c|c|c|c|c|c|c|c|c|c|c|c|c|c|c|c|c|c|c|}
\hline Country & $\begin{array}{l}\text { Number of } \\
\text { partnerships }\end{array}$ & $\begin{array}{l}\text { Proportion of all } \\
\text { partnerships (\%) }\end{array}$ & Academic & $\%$ & $\begin{array}{l}\text { Research } \\
\text { Institute }\end{array}$ & $\%$ & $\begin{array}{l}\text { Industry } \\
\text { (SME) }\end{array}$ & $\%$ & $\begin{array}{l}\text { Industry } \\
\text { (large) }\end{array}$ & $\%$ & $\begin{array}{l}\text { Industry } \\
\text { (total) }\end{array}$ & $\%$ & $\begin{array}{l}\text { Other (inc. } \\
\text { consultants) }\end{array}$ & $\%$ & $\begin{array}{l}\text { No. of projects } \\
\text { coordinated }\end{array}$ & $\%$ & $\begin{array}{l}\text { Number of } \\
\text { partners }\end{array}$ & $\begin{array}{l}\text { Proportion of all } \\
\text { partners (\%) }\end{array}$ \\
\hline Germany & 230 & 20.5 & 79 & 15.1 & 65 & 25.2 & 39 & 29.3 & 27 & 19.0 & 66 & 24.0 & 20 & 30.3 & 23 & 21.3 & 129 & 19.5 \\
\hline UK & 136 & 12.1 & 82 & 15.7 & 9 & 3.5 & 19 & 14.3 & 18 & 12.7 & 37 & 13.5 & 8 & 12.1 & 15 & 13.9 & 84 & 12.7 \\
\hline France & 120 & 10.7 & 35 & 6.7 & 54 & 20.9 & 7 & 5.3 & 20 & 14.1 & 27 & 9.8 & 4 & 6.1 & 9 & 8.3 & 64 & 9.7 \\
\hline Italy & 104 & 9.3 & 38 & 7.3 & 30 & 11.6 & 13 & 9.8 & 17 & 12.0 & 30 & 10.9 & 6 & 9.1 & 14 & 13.0 & 58 & 8.8 \\
\hline Netherlands & 63 & 5.6 & 34 & 6.5 & 9 & 3.5 & 3 & 2.3 & 12 & 8.5 & 15 & 5.5 & 5 & 7.6 & 7 & 6.5 & 35 & 5.3 \\
\hline Spain & 50 & 4.5 & 27 & 5.2 & 14 & 5.4 & 6 & 4.5 & 1 & 0.7 & 7 & 2.5 & 2 & 3.0 & 4 & 3.7 & 34 & 5.1 \\
\hline Sweden & 45 & 4.0 & 36 & 6.9 & 1 & 0.4 & 0 & 0.0 & 4 & 2.8 & 4 & 1.5 & 4 & 6.1 & 6 & 5.6 & 16 & 2.4 \\
\hline Belgium & 44 & 3.9 & 27 & 5.2 & 5 & 1.9 & 3 & 2.3 & 5 & 3.5 & 8 & 2.9 & 4 & 6.1 & 3 & 2.8 & 22 & 3.3 \\
\hline Switzerland & 38 & 3.4 & 18 & 3.4 & 5 & 1.9 & 5 & 3.8 & 8 & 5.6 & 13 & 4.7 & 2 & 3.0 & 3 & 2.8 & 22 & 3.3 \\
\hline Denmark & 36 & 3.2 & 21 & 4.0 & 2 & 0.8 & 4 & 3.0 & 7 & 4.9 & 11 & 4.0 & 2 & 3.0 & 1 & 0.9 & 22 & 3.3 \\
\hline Austria & 30 & 2.7 & 17 & 3.3 & 0 & 0.0 & 5 & 3.8 & 7 & 4.9 & 12 & 4.4 & 1 & 1.5 & 1 & 0.9 & 21 & 3.2 \\
\hline Finland & 28 & 2.5 & 13 & 2.5 & 6 & 2.3 & 3 & 2.3 & 5 & 3.5 & 8 & 2.9 & 1 & 1.5 & 5 & 4.6 & 18 & 2.7 \\
\hline Ireland & 24 & 2.1 & 16 & 3.1 & 0 & 0.0 & 5 & 3.8 & 3 & 2.1 & 8 & 2.9 & 0 & 0.0 & 5 & 4.6 & 12 & 1.8 \\
\hline Poland & 24 & 2.1 & 9 & 1.7 & 9 & 3.5 & 5 & 3.8 & 0 & 0.0 & 5 & 1.8 & 1 & 1.5 & 1 & 0.9 & 21 & 3.2 \\
\hline Greece & 21 & 1.9 & 8 & 1.5 & 9 & 3.5 & 1 & 0.8 & 1 & 0.7 & 2 & 0.7 & 2 & 3.0 & 3 & 2.8 & 11 & 1.7 \\
\hline Israel & 20 & 1.8 & 17 & 3.3 & 2 & 0.8 & 0 & 0.0 & 1 & 0.7 & 1 & 0.4 & 0 & 0.0 & 1 & 0.9 & 8 & 1.2 \\
\hline $\begin{array}{l}\text { Czech } \\
\text { Republic }\end{array}$ & 17 & 1.5 & 7 & 1.3 & 5 & 1.9 & 5 & 3.8 & 0 & 0.0 & 5 & 1.8 & 0 & 0.0 & 0 & 0.0 & 13 & 2.0 \\
\hline Russia & 12 & 1.1 & 3 & 0.6 & 8 & 3.1 & 0 & 0.0 & 1 & 0.7 & 1 & 0.4 & 0 & 0.0 & 0 & 0.0 & 6 & 0.9 \\
\hline Hungary & 9 & 0.8 & 3 & 0.6 & 4 & 1.6 & 1 & 0.8 & 1 & 0.7 & 2 & 0.7 & 0 & 0.0 & 1 & 0.9 & 7 & 1.1 \\
\hline Norway & 9 & 0.8 & 3 & 0.6 & 2 & 0.8 & 2 & 1.5 & 1 & 0.7 & 3 & 1.1 & 1 & 1.5 & 3 & 2.8 & 6 & 0.9 \\
\hline Portugal & 9 & 0.8 & 5 & 1.0 & 4 & 1.6 & 0 & 0.0 & 0 & 0.0 & 0 & 0.0 & 0 & 0.0 & 0 & 0.0 & 8 & 1.2 \\
\hline Slovenia & 9 & 0.8 & 1 & 0.2 & 5 & 1.9 & 2 & 1.5 & 1 & 0.7 & 3 & 1.1 & 0 & 0.0 & 0 & 0.0 & 6 & 0.9 \\
\hline Turkey & 6 & 0.5 & 5 & 1.0 & 0 & 0.0 & 0 & 0.0 & 0 & 0.0 & 0 & 0.0 & 1 & 1.5 & 1 & 0.9 & 4 & 0.6 \\
\hline Bulgaria & 4 & 0.4 & 1 & 0.2 & 0 & 0.0 & 3 & 2.3 & 0 & 0.0 & 3 & 1.1 & 0 & 0.0 & 1 & 0.9 & 4 & 0.6 \\
\hline Lithuania & 4 & 0.4 & 3 & 0.6 & 1 & 0.4 & 0 & 0.0 & 0 & 0.0 & 0 & 0.0 & 0 & 0.0 & 0 & 0.0 & 3 & 0.5 \\
\hline Romania & 4 & 0.4 & 2 & 0.4 & 2 & 0.8 & 0 & 0.0 & 0 & 0.0 & 0 & 0.0 & 0 & 0.0 & 0 & 0.0 & 4 & 0.6 \\
\hline Slovakia & 4 & 0.4 & 1 & 0.2 & 2 & 0.8 & 1 & 0.8 & 0 & 0.0 & 1 & 0.4 & 0 & 0.0 & 0 & 0.0 & 4 & 0.6 \\
\hline USA & 4 & 0.4 & 3 & 0.6 & 0 & 0.0 & 0 & 0.0 & 1 & 0.7 & 1 & 0.4 & 0 & 0.0 & 0 & 0.0 & 4 & 0.6 \\
\hline China & 3 & 0.3 & 1 & 0.2 & 2 & 0.8 & 0 & 0.0 & 0 & 0.0 & 0 & 0.0 & 0 & 0.0 & 0 & 0.0 & 3 & 0.5 \\
\hline Estonia & 3 & 0.3 & 2 & 0.4 & 0 & 0.0 & 1 & 0.8 & 0 & 0.0 & 1 & 0.4 & 0 & 0.0 & 0 & 0.0 & 2 & 0.3 \\
\hline Latvia & 3 & 0.3 & 3 & 0.6 & 0 & 0.0 & 0 & 0.0 & 0 & 0.0 & 0 & 0.0 & 0 & 0.0 & 0 & 0.0 & 2 & 0.3 \\
\hline Brazil & 1 & 0.1 & 0 & 0.0 & 0 & 0.0 & 0 & 0.0 & 0 & 0.0 & 0 & 0.0 & 1 & 1.5 & 0 & 0.0 & 1 & 0.2 \\
\hline Cyprus & 1 & 0.1 & 0 & 0.0 & 0 & 0.0 & 0 & 0.0 & 0 & 0.0 & 0 & 0.0 & 1 & 1.5 & 0 & 0.0 & 1 & 0.2 \\
\hline Iceland & 1 & 0.1 & 0 & 0.0 & 0 & 0.0 & 0 & 0.0 & 1 & 0.7 & 1 & 0.4 & 0 & 0.0 & 0 & 0.0 & 1 & 0.2 \\
\hline Japan & 1 & 0.1 & 1 & 0.2 & 0 & 0.0 & 0 & 0.0 & 0 & 0.0 & 0 & 0.0 & 0 & 0.0 & 0 & 0.0 & 1 & 0.2 \\
\hline Luxembourg & 1 & 0.1 & 0 & 0.0 & 1 & 0.4 & 0 & 0.0 & 0 & 0.0 & 0 & 0.0 & 0 & 0.0 & 1 & 0.9 & 1 & 0.2 \\
\hline Mexico & 1 & 0.1 & 0 & 0.0 & 1 & 0.4 & 0 & 0.0 & 0 & 0.0 & 0 & 0.0 & 0 & 0.0 & 0 & 0.0 & 1 & 0.2 \\
\hline Serbia & 1 & 0.1 & 0 & 0.0 & 1 & 0.4 & 0 & 0.0 & 0 & 0.0 & 0 & 0.0 & 0 & 0.0 & 0 & 0.0 & 1 & 0.2 \\
\hline Ukraine & 1 & 0.1 & 1 & 0.2 & 0 & 0.0 & 0 & 0.0 & 0 & 0.0 & 0 & 0.0 & 0 & 0.0 & 0 & 0.0 & 1 & 0.2 \\
\hline Total & 1121 & 100 & 522 & 100 & 258 & 100 & 133 & 100 & 142 & 100 & 275 & 100 & 66 & 100 & 108 & 100 & 661 & 100 \\
\hline
\end{tabular}


Partnerships by EU status

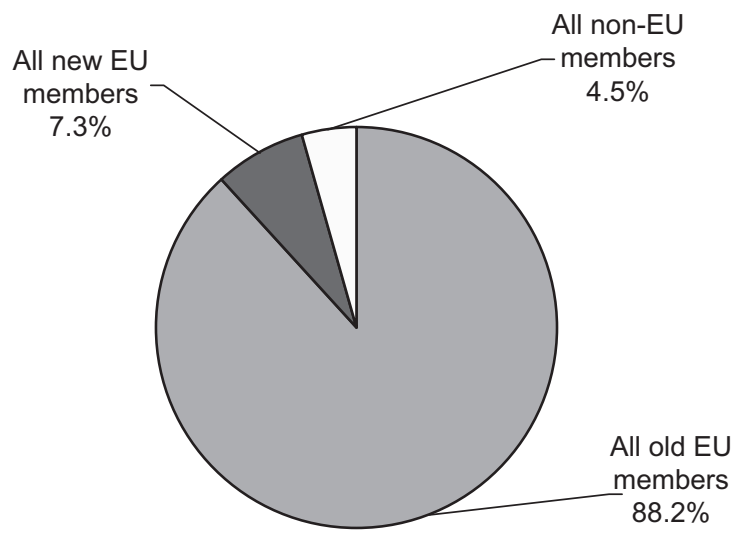

Fig. 1. Proportion of partnerships by EU status.

the research network, they tend to do this in the context of more focused projects and smaller networks characteristic of the STREP instrument. The central role of universities and research institutes in coordinating networks is likely to further emphasise the emergent nature of nanotechnology, with companies largely exploring the field. It also suggests that universities and research institutions need advanced organisational capabilities for managing institutionally and nationally diverse research networks in the emergent technology fields-a phenomenon usually studied from the focal point of a private company and rarely from the perspective of a public research institution.

A more clinical look into the activity of individual institutions identifies a cluster of research institutes that top the list of partners with the most network partnerships (see Table 6). From the data available, it was not possible to identify the roles these partners held in research networks, but it is evident that large research institutes play a central role in collaborative projects in nanotechnology. A handful of large companies is also found on the list, suggesting a strategic focus on nanotechnology-related innovation.

A more nuanced picture of the variance in institutional structure can be observed through an analysis of the participation of different types of partners within different research topics. According to the Chi-squared test (Table 7), the institutional structure of partners in the research topic Fundamentals significantly differs $(p<0.001)$ when compared to the topics Nano-engineering and Applications. Similarly, the institutional structure of Nano-biotechnology research networks is significantly different $(p<0.001)$ when compared to research networks within the topic Handling and Control Devices and Applications. Perhaps surprisingly, the industry structure of Nano-engineering and Handling and Control Devices also significantly differ $(p<0.001)$ from each other. The Pearson residual shows that academic and large industrial partners make the largest contribution to the differences in the structure of institutional partners. Academic partners dominate in projects centred on Fundamentals, Nano-biotechnology and Handling and Control Devices, which may be explained by their competency in scientific research. Meanwhile, large companies tend to increase their participation in projects centred on Applications, which suggests that they are more strategically focused on research that is closer to market. It is surprising that the participation of SMEs is much more evenly spread among all the topics, because it would be conventional to assume that these companies would focus on more applied topics. The explanation for this pattern of SMEs' participation could not be further explored with our available data. However, this pattern indicates that the research strategies of SMEs involved in nanotechnology, as well as the strategic identities of emerging nanotechnology

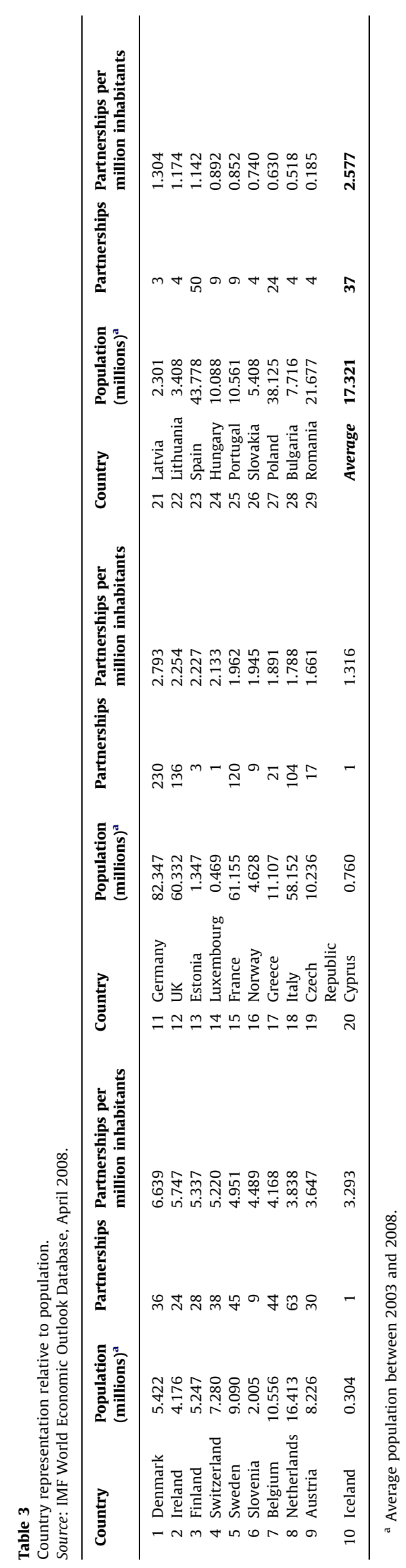


Table 4

Comparison of institutional members of nanotechnology research networks.

\begin{tabular}{|c|c|c|c|c|c|c|c|c|c|c|c|c|c|c|c|}
\hline \multirow[t]{2}{*}{ Partner type } & \multicolumn{5}{|c|}{ Data description } & \multicolumn{6}{|c|}{ Pairwise comparison output } & \multicolumn{4}{|c|}{ Regression results } \\
\hline & No. & Min. & Max. & Mean & SD & Academic & RI & Ind $(1)$ & Ind (SME) & Ind(total) & Consult. & Estimate & SD. error & $T$-value & $\operatorname{Pr}(>|t|)$ \\
\hline Academic & 522 & 1 & 12 & 1.91 & 1.66 & - & - & - & - & - & - & 1.93 & 0.11 & 17.74 & $<0.001$ \\
\hline Research Institute & 258 & 1 & 25 & 2.43 & 4.14 & 0.026 & - & - & - & - & - & 0.52 & 0.20 & 2.54 & 0.011 \\
\hline Large industry & 142 & 1 & 7 & 1.34 & 0.92 & 0.011 & $<\mathbf{0 . 0 0 1}$ & - & - & - & - & -0.58 & 0.20 & -2.86 & 0.004 \\
\hline SME industry & 133 & 1 & 2 & 1.10 & 0.30 & $<0.001$ & $<\mathbf{0 . 0 0 1}$ & 0.543 & - & - & - & -0.81 & 0.19 & -4.17 & $<0.001$ \\
\hline Industry total & 275 & 1 & 7 & 1.21 & 0.68 & $<0.001$ & $<0.001$ & 0.798 & 0.798 & - & - & -0.70 & 0.16 & -4.39 & $<0.001$ \\
\hline Consultancy & 45 & 1 & 3 & 1.25 & 0.55 & 0.07 & 0.002 & 0.876 & 0.805 & 0.912 & - & -0.66 & 0.31 & -2.11 & 0.035 \\
\hline Other & 21 & 1 & 2 & 1.05 & 0.22 & 0.07 & 0.004 & 0.798 & 0.912 & 0.805 & 0.805 & -0.86 & 0.41 & -2.10 & 0.036 \\
\hline
\end{tabular}

\section{Coordinators by EU status}

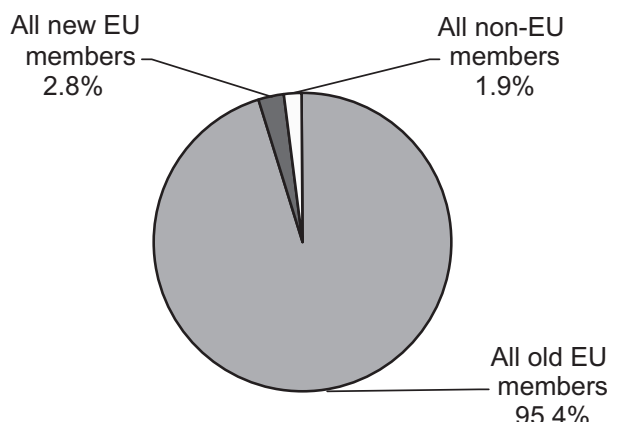

Coordinators by partner type

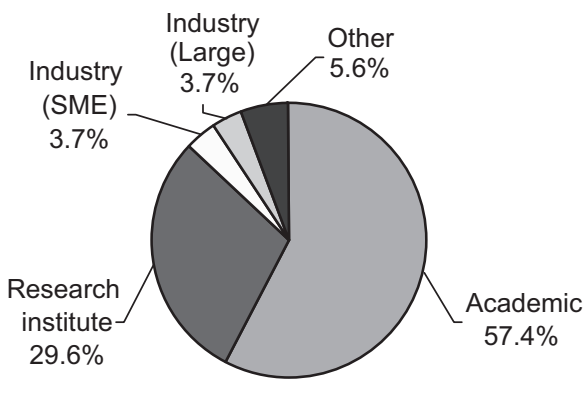

Fig. 2. Project coordinators by EU status and partner type.

Table 5

Coordinators by instrument and partner type.

\begin{tabular}{lclll}
\hline & STREP & $\begin{array}{l}\text { Integrated } \\
\text { Project }\end{array}$ & $\begin{array}{l}\text { Network of } \\
\text { Excellence }\end{array}$ & CSA \\
\hline Academic & 51 & 7 & 3 & 1 \\
Research Institute & 24 & 2 & 2 & 4 \\
Industry (SME) & 2 & 1 & 0 & 1 \\
Industry (large) & 4 & 0 & 0 & 0 \\
Total industry & 6 & 1 & 0 & 1 \\
Other & 2 & 2 & 0 & 2 \\
Total=108 & $\mathbf{8 3}$ & $\mathbf{1 2}$ & $\mathbf{5}$ & $\mathbf{8}$ \\
\hline
\end{tabular}

companies, may warrant special research attention. The evenly spread participation of research institutes indicates their broad competency, and breadth of research interests.

The above data provides evidence of variability in institutional configurations among collaborative projects. Fig. 3 provides some indicative evidence about the institutional diversity within projects. The shapes of frequency distributions differ between academic institutions and research institutes on one hand, and large firms and SMEs on the other. The most common number of academic partners ranges from 2 to 6 , and projects without academic partners are rather exceptional. Such exceptions are more frequent with research institutes, although it is still rare to identify a project without a single research institute involved. However, the same cannot be said for industrial participation. There are a considerable number of projects with no SME involvement ( $n=46$, or $43 \%$ of all projects) and almost as many projects with no large firm involvement $(n=45$, or $42 \%$ of all projects). The evidence shows, however, that the number of projects with no industry partner of either type is much lower $(n=25$, or $23 \%)$. Most collaborative projects involve a single industrial partner, and after such a sole representation, the frequency of industrial participation gradually decreases. Such frequency patterns of industrial participation indicate that research networks pay serious attention to involving at least one industrial partner. They also show that in nanotechnology collaborative projects, industry-university collaboration is much more frequent than collaboration between industrial partners. It is evident that academic partners and research institutes form the bulk of project members. The number of academic partners per project is slightly higher than at research institutes.

Table 8 and Fig. 4 provide data helping to analyse the diversity of nanotechnology research projects by considering both institutional and international diversity by research instrument. It is evident that IP networks are clustered together, with high institutional diversity and reasonable international diversity. IP projects represent research networks engaged with highly uncertain and long-term research programmes, and this high institutional diversity indicates that the policy goal of achieving critical mass of resources and expertise across European institutions is met. There is no clear pattern for STREP projects, which are evenly spread across the landscape with various degrees of institutional and international diversity. Such widespread positioning of STREP projects seems in line with EU policy, since these projects address narrower research challenges, and the variety in research problems may determine the variety in institutional and international configurations. CSA projects dedicated to networking, disseminating and training activities are, on average, the most internationally diverse and the least institutionally diverse. A few isolated research projects can be observed, most of which belong to the STREP instrument. There is a small group of projects with minimal institutional diversity and a similarly small group of projects with extreme international diversity.

In summary, Fig. 4 shows that European nanotechnology projects are indisputably diverse along both institutional and international dimensions. There is no cluster of projects where both institutional and international diversity are low, and the group of projects with low institutional diversity is small and inconsequential. This confirms that European nanotechnology research networks face significant challenges for managing institutional and international diversity. 
Table 6

Top 50 partners considering number of partnerships.

\begin{tabular}{|c|c|c|c|c|}
\hline No. & Academic partners & $\begin{array}{l}\text { No. of projects } \\
\text { involved in }\end{array}$ & Partner type & $\begin{array}{l}\text { No. of projects } \\
\text { coordinated }\end{array}$ \\
\hline 1 & Consiglio Nazionale delle Ricerche (CNR) & 25 & Research Institute & 4 \\
\hline 2 & Centre National de la Recherche Scientifique (CNRS) & 23 & Research Institute & 1 \\
\hline 3 & Max-Planck Institute for Chemical Physics of Solids & 20 & Research Institute & 2 \\
\hline 4 & Fraunhofer Gesellschaft & 16 & Research Institute & 3 \\
\hline 5 & Commissariat a l'Energie Atomique & 14 & Research Institute & 4 \\
\hline 6 & Lund University & 12 & Academic & 2 \\
\hline 7 & Katholieke Universiteit Leuven & 11 & Academic & 1 \\
\hline 8 & CSIC & 9 & Research Institute & 2 \\
\hline 9 & EPFL & 9 & Academic & 1 \\
\hline 10 & Universiteit Twente & 8 & Academic & 2 \\
\hline 11 & Tel Aviv University & 8 & Academic & 1 \\
\hline 12 & Chalmers University of Technology & 7 & Academic & 3 \\
\hline 13 & Tyndall National Institute at University College, Cork & 7 & Academic & 2 \\
\hline 14 & Technische Universität München & 7 & Academic & 1 \\
\hline 15 & Universita di Bologna & 7 & Academic & 1 \\
\hline 16 & Philips Electronics Nederland BV & 7 & Industry (large) & 1 \\
\hline 17 & Russian Academy of Sciences & 7 & Research Institute & - \\
\hline 18 & University of Cambridge & 6 & Academic & 1 \\
\hline 19 & Ludwig-Maximilians Universität, Munich & 6 & Academic & - \\
\hline 20 & Technical University of Denmark & 6 & Academic & - \\
\hline 21 & Technische Universiteit Eindhoven & 5 & Academic & 1 \\
\hline 22 & University of Nottingham & 5 & Academic & 1 \\
\hline 23 & VTT Espoo & 5 & Research Institute & 1 \\
\hline 24 & Hebrew University at Jerusalem & 5 & Academic & - \\
\hline 25 & Saarland University & 5 & Academic & - \\
\hline 26 & Universität Münster & 5 & Academic & - \\
\hline 27 & University of Copenhagen & 5 & Academic & - \\
\hline 28 & University of Southampton & 5 & Academic & - \\
\hline 29 & Thales Group & 5 & Industry (large) & - \\
\hline 30 & EU Joint Research Centre & 5 & Research Institute & - \\
\hline 31 & Institut national de la santé et de la recherche médicale (INSERM) & 5 & Research Institute & - \\
\hline 32 & Leibniz-Institut & 5 & Research Institute & - \\
\hline 33 & University of Birmingham & 4 & Academic & 3 \\
\hline 34 & AIXTRON AG & 4 & Industry (large) & 2 \\
\hline 35 & Johann Gutenberg Universität Mainz & 4 & Academic & 1 \\
\hline 36 & Kungliga Tekniska Högskolan (Royal Institute of Technology) & 4 & Academic & 1 \\
\hline 37 & Trinity College Dublin & 4 & Academic & 1 \\
\hline 38 & University of Crete & 4 & Academic & 1 \\
\hline 39 & Johannes Kepler Universität, Linz & 4 & Academic & - \\
\hline 40 & Linköping Universitet & 4 & Academic & - \\
\hline 41 & Universita di Genova & 4 & Academic & - \\
\hline 42 & Université Paris Sud XI & 4 & Academic & - \\
\hline 43 & Universiteit Groningen & 4 & Academic & - \\
\hline 44 & University College London & 4 & Academic & - \\
\hline 45 & University of Helsinki & 4 & Academic & - \\
\hline 46 & University of Newcastle & 4 & Academic & - \\
\hline 47 & BASF & 4 & Industry (large) & - \\
\hline 48 & Centre Suisse d'Electronique et de Microtechnique SA & 4 & Industry (large) & - \\
\hline 49 & Forschungszentrum Karlsruhe, Institute for Nanotechnology & 4 & Research Institute & - \\
\hline 50 & NCSR (National Centre of Scientific Research) Demokritos & 4 & Research Institute & - \\
\hline
\end{tabular}

Table 7

Comparison of institutional structure among different research topics in the nanotechnology programme.

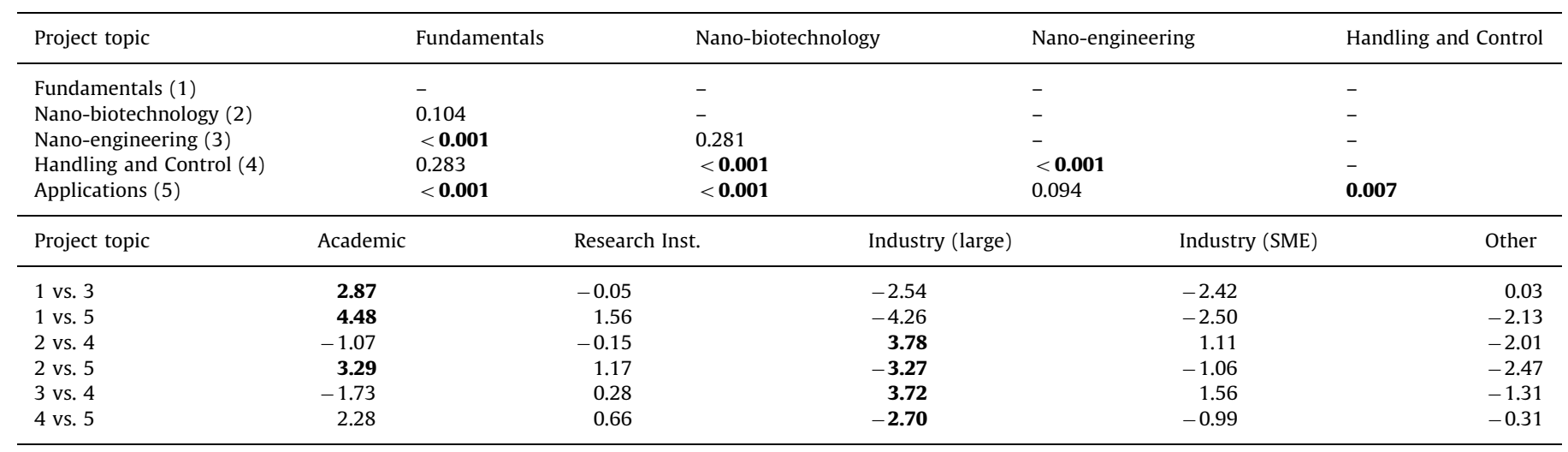



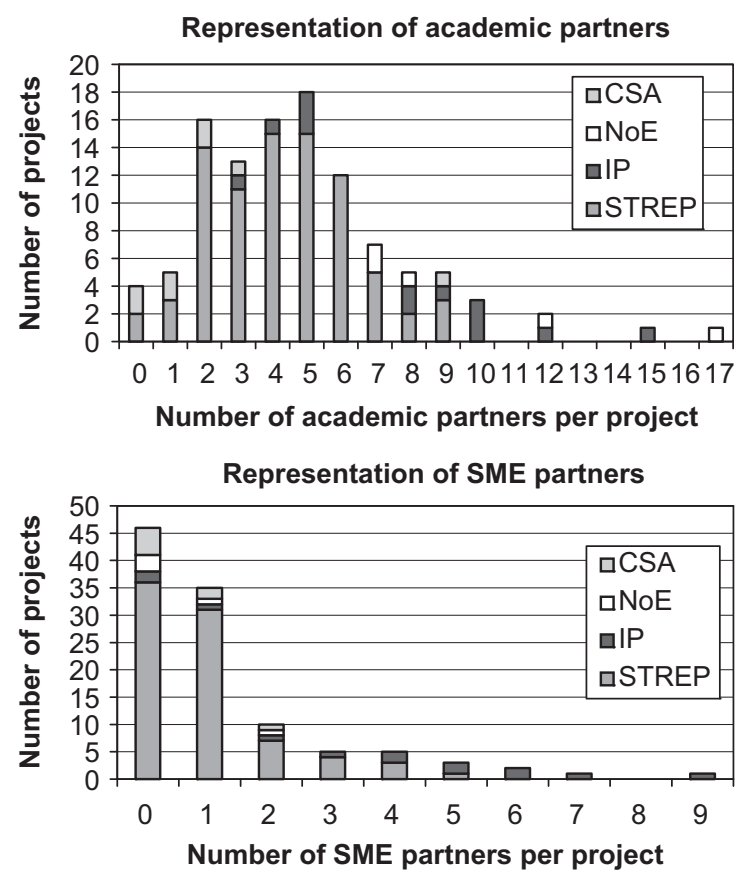

Representation of research institute partners

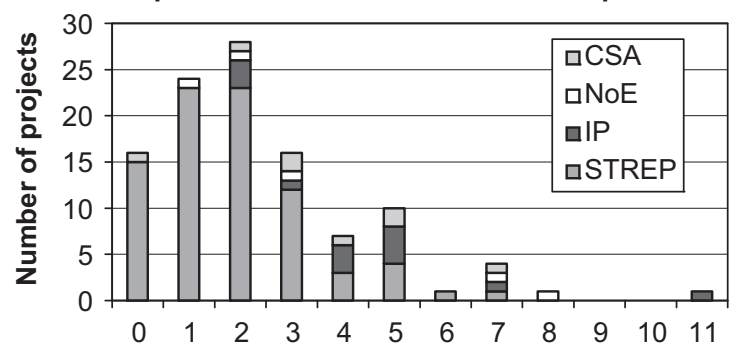

Number of research institute partners per project

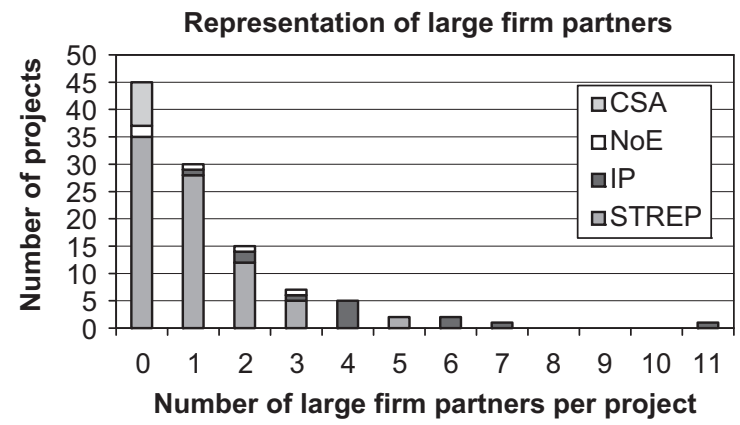

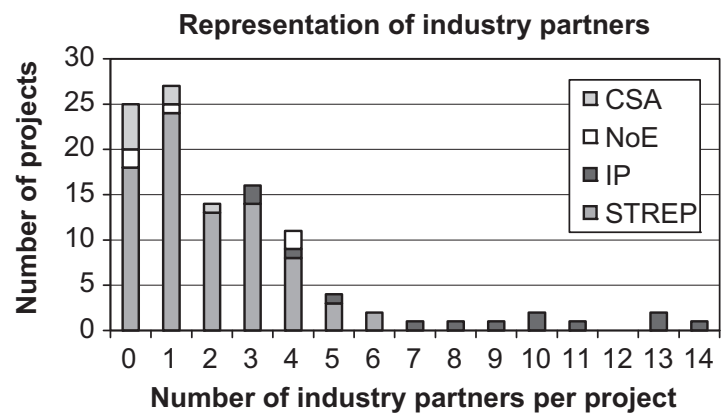

Fig. 3. Representation of partner types in different policy instruments.

Table 8

Description of international and institutional diversity by instrument type.

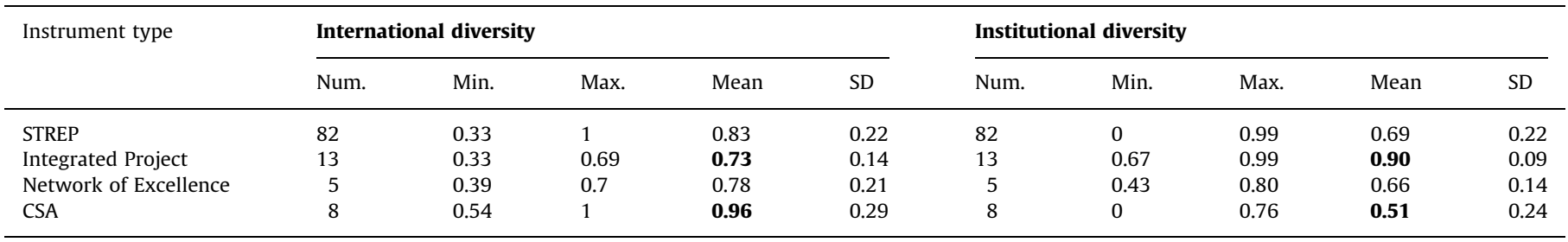

\section{Discussion and conclusion}

This paper was aimed at unveiling the international and institutional configurations of nanotechnology research networks in Europe. The evidence from our data clearly suggests that most of the research networks funded by the EC are notably diverse in terms of the international and institutional affiliations of their constituting members. This diversity reflects the effectiveness of the fundamental policy goals of subsidiarity, cohesion and industrial pre-competitiveness, as well as the general-purpose nature of nanotechnology that implies widespread dispersion of knowledge among a variety of members in this system of emergent technology innovation.

The recognition of collaborative diversity exposes the number of challenges that policy-makers face when shaping the research policy of emerging nanotechnology. The first challenge concerns the extent of policy influence on the international and institutional configurations of research networks. Secondly, the avowed diversity of research networks highlights the need for network members to have capability in managing collaborative research and in extracting benefits from participating in collaborative projects. Such management capability should not be mistaken for a narrow project management and administrative competency, usually viewed as the ability to provide written reports in accordance with EC specifications. Both of these issues are highly relevant to the future structure of research in Europe.

We find that the EC effectively institutionalises the international diversity of the research networks; however, it is still evident that new member states in particular lag behind more established members in terms of number of partnerships. Although this is not surprising due to new member states' history, with future FPs likely to show an increase in their participation, 


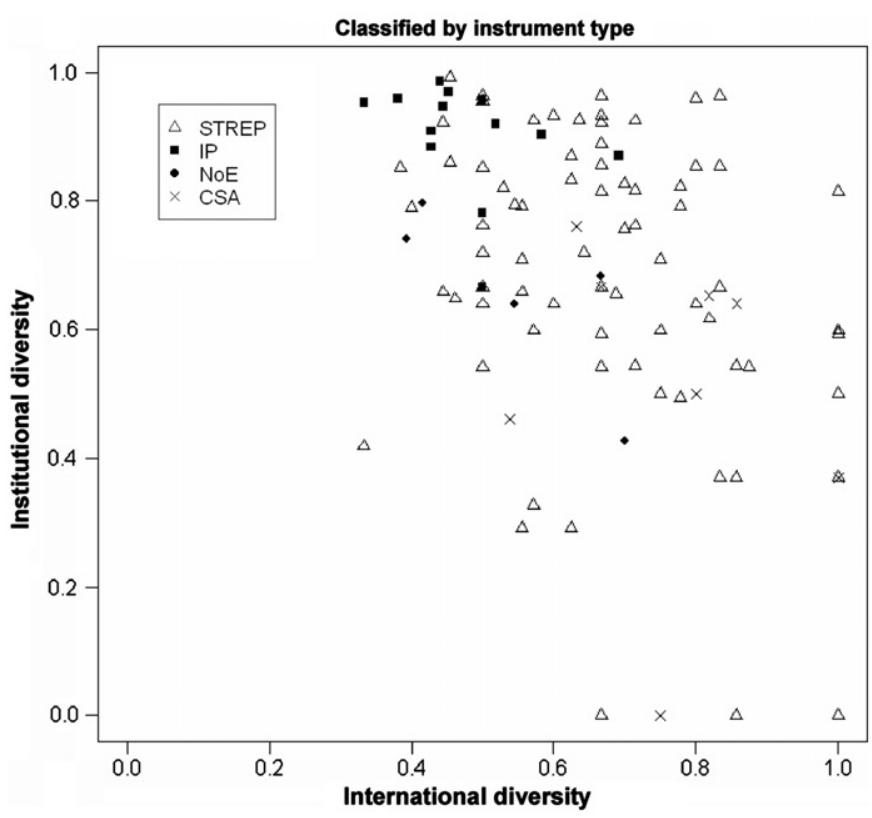

Fig. 4. Composition of collaborative diversity in nanotechnology research networks.

their currently extremely low representation as project coordinators indicates that research leadership remains strongly in the hands of traditional research powerhouses. This could be due to their superior research and management capabilities, but the coordinator role also suggests centrality in research networks, which implies that the benefits of research are not necessary equally distributed among project members. This suggests that while international diversity is extremely important in order to achieve cohesion and is likely to play a key role in the dispersion of knowledge about nanotechnology, it is important to validate whether the benefits of project participation are equally distributed among the members of research networks. In other words, international diversity is a necessary but not sufficient condition for achieving cohesion among EU member states in the area of emergent nanotechnology.

The significant degree of institutional diversity in nanotechnology networks suggests that the research policy of industrial pre-competitiveness is well served. A closer look into institutional diversity suggests that nanotechnology research networks are predominantly populated by academic institutions and research institutes, with industrial partners often participating in small numbers within projects. This is, again, not surprising and reflects the emerging nature of nanotechnology. It emphasises, however, that nanotechnology research networks are characterised by industry-university/research institute collaboration, while collaboration among industry members within nanotechnology networks is less intense. It is also evident that different policy instruments mediate the institutional structure of networks, especially concerning academic institutions and large companies. Inter-firm collaboration is more evident in large Integrated Projects than in STREPs or NoEs. The evidence also suggests that large companies target different instruments and topics strategically, and tend to focus on networks with a more strongly applied orientation. In contrast, SMEs' engagement in nanotechnology networks seems to follow a less clear pattern. It is possible that the participating SMEs represent emerging companies that build their identity on nanotechnology, and the less clear pattern of participation in different topics reflects the variety of potential applications perused by such companies.

The diversity that we have identified in nanotechnology research networks certainly emphasises the need for managerial capability by all partners in order to achieve overall project goals and to explore individually the benefits of collaborative research. In order to exploit these collaborative advantages and avoid collaborative inertia, project participants must be able to deal with key managerial challenges such as ambiguity, complexity and dynamic shifts (Huxham and Vangen, 2000, 2004)_both jointly and individually. Hence, organisational capabilities for research in collaborative environments and leadership to avoid pitfalls of sharing knowledge over national and institutional borders are equally instrumental for delivering research with high impact.

Perhaps more importantly, such capabilities could influence the shaping of future European nanotechnology innovation systems. It may be argued that due to the principle of subsidiarity, the EC is unlikely to favour the establishment of national research champions in emerging technology areas. Instead, the EC will be more likely to prefer the creation of research networks capable of providing high-impact research. The configuration and stability of such networks is highly likely to be determined by their members' capability to manage collaborative diversity and spread benefits equally among the participating members. On one hand, if strategic capabilities of managing institutionally and nationally diverse networks are unevenly spread among the members of a nanotechnology innovation system, the ERA is more likely to be populated by ad hoc research networks, dominated by partners with excellent research and management capabilities, which pragmatically select partners in order to meet the explicitly or implicitly set criteria for international and institutional diversity. If, on the other hand, capability for research in nationally and institutionally diverse networks is recognised as a strategic asset by participating members, we may expect more stable collaborative arrangements in which stable research networks benefit from continuity and organisational learning. This compensates for the impediments of managing across institutional and national borders.

\subsection{Limitations and future research}

Our study has a number of limitations. The data collected originates from the EC's Thematic Priority 3 (NMP), which is explicitly focused on nanotechnology. Nanotechnology collaborative projects are, however, also funded within other thematic priorities, most notably in Information and Communication Technology. These nanotechnology-centred projects outside the dedicated Thematic Priority 3 were not included in our study. The inclusion of ICT research projects may provide different evidence of industrial engagement. For example, it is well documented that large semiconductor companies, following their precise technology roadmaps, engage greatly in research on the nanotechnology applications.

This research study was aimed at unveiling the emerging configurations and structures of nanotechnology research networks in the ERA. Generating theoretical inferences on research management in collaborative and diverse networks is largely outside the scope of this study. These limitations are, however, also an invitation for future research. We believe it would be fruitful to explore the research performance of differently diverse collaborative networks. At this stage, patent data from the studied collaborative projects remain very scarce, since the majority of projects are not yet completed-however, future research that incorporates this data once it becomes available could enhance our knowledge about the EU's nanotechnology research framework further.

In addition, a more in-depth understanding of managerial practice and processes in diverse collaborative research environments could be obtained by in-depth qualitative work. Polar cases, which compare settings with different levels of institutional and international diversity, could shed more light on capabilities for collaborative research. They may also challenge the current 
perception that research management in FP is all about narrow project management and administration of project reports.

FP7 is nearing its mid-point and the NMP programme is much larger in scope and budget ( $€ 3.5$ billion). Data for FP7 could become available soon and it may be fruitful to begin studying the stability and variability of nanotechnology research networks as the programme moves to its conclusion in 2013. Moreover, FP7 has made use of new and progressively larger networked research instruments to drive greater European research cohesion through: (a) public (EU): public (member state) partnerships such as the ERA Net Plus and Article 169 initiatives; and (b) public (EU): private (industry) partnerships such as the Joint Technology Initiatives and the three new Private Public Partnerships initiatives, namely the 'green car', 'energy-efficient house' and 'factories of the future' led by the NMP. We believe the research methodologies we have demonstrated in this paper not only can be continued to compare the results of the core NMP programme in FP7 with those of FP6 but also might be extended to analyse the effectiveness of FP7's new larger integrating instruments.

\subsection{Conclusions}

We have studied institutional and international diversity in emerging nanotechnology research networks within the European Research Area. The evidence obtained shows that these research networks are characterised by a significant degree of institutional and international diversity-a conclusion with important consequences for European policy-makers as well as for participants in EC-funded research projects. The evidence suggests that European institutional arrangements are effective in creating diverse collaborative networks and the adopted instruments mitigate institutional configurations. This avowed diversity strongly emphasises the need for the development of organisational capabilities among participating members to manage collaborative research strategically across national and institutional borders. The existence of such strategic management capabilities could stabilise nanotechnology research networks and spread the benefits of collaborative research evenly among partners. This could, in turn, increase cohesion in nanotechnology innovation systems and strengthen the impact of collaborative research.

\section{Acknowledgements}

This research was supported by a Marie Curie European Reintegration Grant (PERG02-GA-2007-224801) to the first author. The authors would also like to thank Weiqi Luo for his assistance during the research.

\section{References}

Ahuja, G., 2000. Collaboration networks, structural holes, and innovation: a longitudinal study. Administrative Science Quarterly 45 (3), 425-455.

Alencar, M.S.M., Porter, A.L., Antunes, A.M.S., 2007. Nanopatenting patterns in relation to product life cycle. Technological Forecasting and Social Change 74 (9), 1661-1680.

Archibugi, D., Coco, A., 2004. International partnerships for knowledge in business and academia: a comparison between Europe and the USA. Technovation 24 (7), 517-528.

Arranz, N., Fernandez de Aroyabe, J.C., 2006. Joint R\&D projects: experiences in the context of European technology policy. Technological Forecasting and Social Change 73 (7), 860-885.

Bhat, J.S.A., 2005. Concerns of new technology based industries-the case of nanotechnology. Technovation 25, 457-462.

Bjerregaard, T., 2010. Industry and academia in convergence: micro-institutional dimensions of R\&D collaboration. Technovation 30 (2), 100-108.

Bozeman, B., Laredo, P., Mangematin, V., 2007. Understanding the emergence and deployment of "nano" S\&T. Research Policy 36 (6), 807-812.

Bresnahan, T.F., Trajtenberg, M., 1995. General purpose technologies_engines of growth? Journal of Econometrics 65 (1), 83-108.
Clarysse, B., Muldur, U., 2001. Regional cohesion in Europe? An analysis of how EU public RTD support influences the techno-economic regional landscape. Research Policy 30 (2), 275-296.

Crawley, M.J., 2003. Statistical Computing: An Introduction to Data Analysis Using S-Plus. John Wiley and Sons Ltd, UK.

De Meyer, A., 1993. Management of an international network of industrial R\&D laboratories. R\&D Management 23 (2), 109-120.

Devenport, S., Davies, J., Grimes, C., 1999. Collaborative research programmes: building trust from difference. Technovation 19 (1), 31-40.

Dhanaraj, C., Parkhe, A., 2006. Orchestrating innovation networks. Academy of Management Journal 31 (3), 659-669.

Dosi, G., 1982. Technological paradigms and technological trajectories: a suggested interpretation of the determinants and direction of technological change. Research Policy 11 (3), 147-162.

Dosi, G., Llerena, P., Labini, M.S., 2006. The relationships between science, technologies and their industrial exploitation: an illustration through the myths and realities of the so-called 'European paradox'. Research Policy 35 (10), 1450-1464.

European Commission, 2004. Towards a European Strategy for Nanotechnology Research DG, Brussels.

European Commission, 2005a. Nanosciences and Nanotechnologies: An Action Plan for Europe 2005-2009. Research DG, Brussels.

European Commission, 2005b. Expert Advisory Group Mid-Term Review Position Paper. EC 31 January, 2005.

European Commission, 2007. Nanosciences and Nanotechnologies: An Action Plan for Europe 2005-2009: First Implementation Report 2005-2007. Research DG Brussels.

Hanel, P., St-Pierre, M., 2006. Industry-University collaboration by Canadian manufacturing firms. Journal of Technology Transfer 31 (4), 485-499.

Hansen, M.T., 1999. The search-transfer problem: the role of weak ties in sharing knowledge across organization subunits. Administrative Science Quarterly 44 (1), 82-111.

Hargrave, T.J., Van de Ven, A.H., 2006. A collective action model of institutional innovation. Academy of Management Review 31 (4), 864-888.

Harryson, S., Kliknaite, S., Dudkowski, R., 2008. Flexibility in innovation through external learning: exploring two models for enhanced industry-university collaboration. International Journal of Technology Management 41 (1/2), 109-137.

Heinze, T., Kuhlmann, S., 2008. Across institutional boundaries? Research collaboration in German public sector nanoscience. Research Policy 37 (5) 888-899.

Hong, J.F.L., O, F.K.H., 2009. Conflicting identities and power between communities of practice: the case of IT outsourcing. Management Learning 40 (3), 311.

Huxham, C., Vangen, S., 2000. Ambiguity, complexity and dynamics in the membership of collaboration. Human Relations 53 (6), 771-805.

Huxham, C., Vangen, S., 2004. Doing things collaboratively: realizing the advantage or succumbing to inertia? Organizational Dynamics 33 (2), 190-201.

Huzzard, T., Östergren, K., 2002. When norms collide: learning under organizational hypocrisy. British Journal of Management 13 (S2), S47-S59.

Islam, N., Miyazaki, K., 2009. Nanotechnology innovation system: understanding hidden dynamics of nanoscience fusion trajectories. Technological Forecasting and Social Change 67 (1), 128-140.

Islam, N., Miyazaki, K., 2010. An empirical analysis of nanotechnology research domains. Technovation 30 (4), 229-237.

Kastrinos, N., 1994. Issues of exploitation: evaluating the impact of the European community framework programme on European industry. Technovation 14 (10), 679-688.

Kautt, M., Walsh, S.T., Bittner, K., 2007. Global distribution of micro-nano technology fabrication centers: a portfolio analysis approach. Technological Forecasting and Social Change 74 (9), 1697-1717.

Kellogg, K.C., Orlikowski, W.J., Yates, J.A., 2006. Life in the trading zone: structuring coordination across boundaries in postbureaucratic organizations. Organization Science 17 (1), 22-46.

Kostoff, R.N., Koytcheff, R.G., Lau, C.G.Y., 2007. Global nanotechnology research literature overview. Technological Forecasting and Social Change 74 (9), 1733-1747.

Kuhlmann, S., 2001. Future governance of innovation policy in Europe-three scenarios. Research Policy 30 (6), 953-976.

Laredo, P., 1998. The networks promoted by the framework programme and the questions they raise about its formulation and implementation. Research Policy 27 (6), 589-598.

Lave, J., Wenger, E., 1991. Situated Learning: Legitimate Peripheral Participation. Cambridge University Press, Cambridge.

Linton, J.D., Walsh, S.T., 2008. A theory of innovation for process-based innovations such as nanotechnology. Technological Forecasting and Social Change 75 (5) 583-594.

Luukkonen, T., 1998. The difficulties in assessing the impact of EU framework programmes. Research Policy 27 (6), 599-610.

Luukkonen, T., 2000. Additionality of EU framework programmes. Research Policy 29 (6), 711-724.

Luukkonen, T., 2002. Technology and market orientation in company participation in the EU framework programme. Research Policy 31 (3), 437-455.

Maine, E., Garnsey, E., 2006. Commercializing generic technology: the case of advanced materials ventures. Research Policy 35 (3), 375-393. 
Marin, P.L., Siotis, G., 2008. Public policies towards research joint venture: institutional design and participants' characteristics. Research Policy 37 (6-7), 1057-1065.

Mense-Petermann, U., 2006. Micro-political or inter-cultural conflicts?-an integrating approach. Journal of International Management 12 (3), 302-317.

Murray, F., 2002. Innovation as co-evolution of scientific and technological networks: exploring tissue engineering. Research Policy 31 (8-9), 1389-1403.

Nikulainen, T., Palmberg, C., 2010. Transferring science-based technology to industry-does nanotechnology make a difference? Technovation 30 (1), 3-11.

Pandza, K., Holt, R., 2007. Absorptive and transformative capacities in nanotechnology innovation systems. Journal of Engineering and Technology Management 24 (4), 347-365.

Parkhe, A., 2003. Institutional environments, institutional change and international alliances. Journal of International Management 9 (3), 305-316.

Pavitt, K., 1998. The inevitable limits of EU R\&D funding. Research Policy 27 (6) $559-568$

Pertuzé, J.A., Calder, E.S., Greitzer, E.M., Lucas, W.A., 2010. Best practices for industry-university collaboration. MIT Sloan Management Review 51 (4), 83-90.

Powell, W.W., Koput, K.W., Smith-Doerr, L., 1996. Interorganizational collaboration and the locus of innovation: networks of learning in biotechnology. Administrative Science Quarterly 41 (1), 116-145.

Romig Jr., A.D., Baker, A.B., Johannes, J., Zipperian, T., Eijkel, K., Kirchoff, B., Mani, H.S., Rao, C.N.R., Walsh, S., 2007. An introduction to nanotechnology policy: opportunities and constrains for emerging and established economies. Technological Forecasting and Social Change 74 (9), 1634-1642.

Rothaermel, F.T., Ku, D.N., 2008. Intercluster innovation differentials: the role of research universities. IEEE Transactions on Engineering Management 55 (1), $9-22$.
Salerno, M., Landoni, P., Verganti, R., 2008. Designing foresight studies for nanoscience and nanotechnology (NST) future developments. Technological Forecasting and Social Change 75 (8), 1202-1223.

Santoro, M.D., Chakrabarti, A.K., 2001. Corporate strategic objectives for establishing relationships with university research centers. IEEE Transactions on Engineering Management 48 (2), 157-163.

Santoro, M.D., Chakrabarti, A.K., 2002. Firm size and technology centrality in industry-university interactions. Research Policy 31 (7), 1163-1180.

Santoro, M.D., Bierly, P.E., 2006. Facilitators of knowledge transfer in universityindustry collaborations: a knowledge-based perspective. IEEE Transactions on Engineering management 53 (4), 495-507.

Shinn, T., Lamy, E., 2006. Paths of commercial knowledge: forms and consequences of university-enterprise synergy in scientist-sponsored firms. Research Policy 35 (10), 1465-1476.

Simpson, E.H., 1951. The interpretation of interaction in contingency tables. Journal of the Royal Statistical Society 13, 238-241.

Sirmon, D.G., Lane, P.J., 2004. A model of cultural differences and international alliance performance. Journal of International Business Studies 35 (4), 306-319.

Thoma, G., 2008. Striving for a large market: evidence from a general purpose technologyin action. Industrial and Corporate Change 18 (1), 107-138.

Tsai, W., 2001. Knowledge transfer in interorganizational networks: effects of network position and absorptive capacity on business unit innovation and performance. Academy of Management Journal 44 (5), 996-1004.

Vonortas, N.S., Spivack, R.N., 2006. Managing large research partnerships: examples from the advanced technology program's information infrastructure for health program. Technovation 26 (10), 1101-1110.

Welch, D.E., Welch, L.S., 2008. The importance of language in international knowledge transfer. Management International Review 48 (3), 339-360. 